rev|Psi

Reseña

\title{
Narciso y Eros en la cruz del presente
}

\section{Leandro Drivet ${ }^{1,2^{*}}$}

${ }^{1}$ Consejo Nacional de Investigaciones Científicas y Técnicas

(CONICET, Argentina)

2Facultad de Ciencias de la Educación, Universidad Nacional de

Entre Ríos (UNER, Argentina)

*Correspondencia: leandrodrivet@gmail.com

Recibido: 14 feb. 2021 | 1ra decisión: 14 jun. 2021 | Aceptado: 14 jun. 2021 | Publicado: 23 jun. 2021 
rev|Psi $\begin{aligned} & \begin{array}{l}\text { Narciso y Eros en la cruz del presente } \\ \text { Drivet }\end{array} \\ & \text { ret }\end{aligned}$

\section{Resumen}

Se presenta la reseña del libro:

Abadi, Florencia. (2018). El sacrificio de Narciso. Hecho Atómico Editores, 91 páginas.

Palabras clave: amor, deseo.

\section{Narciso e Eros na cruz do presente}

Resumo: É apresentada a resenha do livro:

Abadi, Florencia. (2018). El sacrificio de Narciso. Hecho Atómico Editores, 91 páginas.

Palavras-chave: amor, desejo.

\section{Narcissus and Eros on the cross of the present}

Abstract: The author presents a review of the following book:

Abadi, Florencia. (2018). El sacrificio de Narciso. Hecho Atómico Editores, 91 pages.

Keywords: love, desire. 
rev|Psi $\begin{aligned} & \text { Narciso y Eros en la cruz del presente } \\ & \text { Drivet }\end{aligned}$

"El que ama ha sacrificado, por así decir, un fragmento de su narcisismo y sólo puede restituírselo a trueque de ser-amado."

Sigmund Freud (1914/2003, p. 95)

En El nacimiento de la tragedia, Friedrich Nietzsche describe la experiencia de lo dionisíaco como una mezcla de espanto y éxtasis delicioso que se produce cuando el principio de individuación pierde consistencia. La aproximación de la fuerza de la primavera, expresa el joven profesor de Basilea, o el influjo de alguna bebida narcótica [narkotischen Getränkes], propician la intensificación de las emociones que desdibujan la subjetividad "hasta llegar al completo olvido de sí" (Nietzsche, 1872/1994, p. 45). Ante este pasaje, una sensación de desconcierto sacude al lector. La palabra "narcótico" deriva de la voz griega narke: parálisis, confusión o entorpecimiento asociados al contacto con el "pez torpedo" [narka] (anguila eléctrica), del cual se nos ilustra en el Menón (Platón, 1987, 80a-c, pp. 299-300). Ésta es una raíz que se halla en "narciso", flor llamada así, según Plutarco (1987, 647b, p. 153), porque produce somnolencia, "aplaca los nervios y produce una pesadez narcotizante”. Ahora bien, ¿cómo podría estar ligada la experiencia dionisíaca del olvido de sí nada menos que a Narciso, quien parece, a todas luces, el ejemplo arquetípico de la incapacidad del descentramiento, un caso agudo del culto de sí mismo? Ocurre que las apariencias engañan y, después de todo, el mito de Narciso no enseña otra cosa. El delicado y feroz ensayo de Florencia Abadi resuelve el enigma: nos rescata de la descaminada interpretación de Narciso como un egoísta, y nos permite pensar esa figura mítica como un ser que no ha llegado a constituir un "sí mismo", que no se conoce (hasta su muerte) ni se ama porque, por fuera de los ecos de la ensoñación materna, jamás ha sido tocado por un tercero. No es contradictorio, entonces, que Narciso sea presentado por Nietzsche en un contexto dionisíaco. Como la historia del espejo que los titanes obsequian con malicia al pequeño Dioniso, el reflejo del hijo de Liríope en la fuente de agua, y no en los ojos de otro, representa "la tragedia del imposible reencuentro del individuo consigo mismo" (Vernant, 1989/2001, p. 161). Ni herido ni reconocido, Narciso muere por su imagen, a expensas de su cuerpo. Ésta es, nos dice Abadi, la clave sacrificial de su destino.

El desarrollo pormenorizado y polifacético de esta hipótesis de lectura abre una vía hermenéutica que le permite a la autora pensar un amplio conjunto de narraciones, que van de la "alta cultura" a las tradiciones populares, y de lo clásico a lo contemporáneo. En un presente hostil a las humanidades, este esquema interpretativo demuestra el valor de la literatura, no sólo por su capacidad para ofrecer goce estético, sino también debido a su fecundidad teórica. Aquí destacaremos que, en particular, interroga de modo insistente a los lectores de Freud, quien, tal vez por no detenerse en el sentido preciso del mito, a menudo confundió el narcisismo con el autoerotismo.

Chesterton expresó con gracia en algún lugar que «de Edipo sólo sabemos que no tenía el complejo». Abadi nos empuja a pensar que Narciso no sufrió de heridas narcisistas. ¿Cómo podría renunciar a la centralidad de sí, y cómo sería capaz, por consiguiente, de amar, quien no pudo desarrollar un "sí mismo"? Ante su imagen, 
que parece por todos los signos corresponderle, reflejada en una fuente "no tocada" por nada ni por nadie -puntualiza Ovidio (1983, p. 56)- Narciso permanece paralizado. Olvidado de comer y de dormir, con un ansia insaciable, sufre impotente ante el amor, y se arroja desesperado a los brazos de ese otro ilusorio en quien encuentra, sin saberlo hasta el final, su ser y su muerte. Su destino de autoconsumición nos devuelve a un Freud que, no por casualidad, encuentra las tentaciones tanáticas cuando, hacia 1920, se entrega a la especulación: actividad vinculada etimológicamente al espejo. Estudiando sobre la vida de los organismos unicelulares se convence de que la degradación de la vida y el deceso están ligados a la intoxicación con los propios -y sólo con los propios- desechos metabólicos. Como si, escapando al riesgo del erotismo, un deseo de muerte sobreviniera a causa de la mismidad. Inesperado reflejo de Narciso bajo el microscopio: De te observationis narratur.

\section{II}

Son diversos los modos con que nuestras tradiciones literarias y filosóficas se han referido a las tensiones entre el principio de individuación y el deseo de fundirse con el todo, entre la consolidación del yo y las fuerzas naturales y sociales que lo preceden y lo sobrepasan, entre la aspiración a la autosuficiencia y la inclinación a la interdependencia. Con aspectos compartidos y con notas singulares, la filología del futuro nietzscheana evocaba la dinámica entre Dioniso y Apolo, mientras que Freud percibía la opuesta complementariedad de la sexualidad y la autoconservación, el principio del placer y el de realidad, Eros y Ananké, Eros y destrucción. Desde estas perspectivas, la vida y la muerte se juegan entre el movimiento y la quietud, oscilando entre el apego al límite y su transgresión, en medio del fluir y el estancamiento, transitando la descarga y la inhibición, la transformación y la conservación. Es en esta constelación de problemas donde puede inscribirse El sacrificio de Narciso, a partir del dualismo entre Eros y Narciso que Florencia Abadi recupera con originalidad de la sabiduría griega. Así como Freud (1932/2006) descubría la complementariedad de los mitos de Hércules y de Prometeo para dar cuenta de la dialéctica de las pasiones, el reconocimiento del carácter contrapuesto y complementario de las figuras de los hijos de Venus y de Liríope es otro de los rasgos destacables de este ensayo. A Narciso, objeto de contemplación, lo detiene el temor a perderse, que le impide poner en juego su deseo. A Eros, por el contrario, lo persigue el miedo a ser identificado, como si el hechizo de la seducción pudiera ser conjurado por la atribución de rasgos fijos. Narciso es el nombre bajo el cual se agrupan la quietud, la inmovilidad, la voluntad de conservación, la estabilidad; Eros comprende la locura, la desintegración, la transitoriedad, el desequilibrio. El sentido así expuesto de las figuras míticas gana consistencia cuando Abadi, subrayando la lucidez de Calderón de la Barca, se detiene en las funciones opuestas cumplidas por las madres del demon y del cazador no cazado. Mientras que Venus propicia involuntariamente, y por la vía de la envidia, el despliegue del deseo de su hijo, Liríope atrapa en el cautiverio de su deseo a Narciso, condenándolo al aislamiento, y a la perpetuación de un estado psicológico larvario.

Abadi desbarata las hipócritas ilusiones de candidez de cierto erotismo contemporáneo, tanto como el arrogante y sobreactuado gesto de rechazo del 
rev|Psi $\begin{aligned} & \text { Narciso y Eros en la cruz del presente } \\ & \text { Drivet }\end{aligned}$

(necesario) momento narcisista en nombre del deseo. Si el joven Nietzsche compone una reivindicación apolínea de la tragedia griega, y Freud insiste, para disgusto de los partidarios del imperio irrestricto del placer, en el valor cultural del principio de realidad y de la renuncia, Abadi apuesta, a contramano de la tradicional e injusta condena de Narciso como un exponente arquetípico de la soberbia y el egoísmo, por la equilibrada reivindicación de los aspectos narcisistas de la subjetividad que permiten resistir la tentación de la locura divina. El campo psicoanalítico encontrará en este libro una voz estimulante y provocadora no sólo para añadir nuevas y estimulantes aristas a nociones y problemas conocidos, sino para tensionar algunos conceptos técnicos. En particular, pero no de modo exclusivo, para pensar por qué si el narcisismo es el amor a la imagen de sí, no puede ser equiparado al egoísmo. En un contexto en el que el desborde subjetivo se articula como mandato, y el deseo, que reclama sus derechos para liberarse de la prisión del "amor" tradicional, llega a mostrarse incapaz de abandonar el protagonismo (Freud insiste en que el deseo es antisocial), el encomio crítico de las dimensiones "sacrificiales" de la subjetividad no es un gesto de menor audacia.

\section{III}

Las lógicas contrapuestas en El sacrificio de Narciso son las del amor y el deseo. Éste es despiadado y caprichoso, inocente [unschuldig] (en otras palabras, perverso), fugaz, inestable, odioso; el amor es protector, equilibrado, conciliador. $\mathrm{Si}$ el erotismo pertenece a la esfera polifónica y amoral de las pulsiones, y se halla movido por la rivalidad y la envidia (Envidia es la tercera figura central de este libro, y resulta imperdible el análisis de las tres representaciones femeninas del ideal envidioso: la Esfinge, la Mantis religiosa, y la estatua del velo de Isis), el amor está asociado a la piedad, al cuidado, a la gratitud, a la complicidad, al recato, al velo. Pero no es el señalamiento de la "contradicción” entre estos ámbitos lo que distingue la tesis de este ensayo. En la provocadora perspectiva de Abadi, la oposición de esas lógicas está signada por la incompatibilidad.

Para Freud, el amor se compone de una corriente sensual y de una tierna, siempre en tensión, pero capaces de crecimiento y armonía en el orden cultural. Éste, por definición, nunca dejará de exigir renuncias. Si pensamos en la metafísica nietzscheana, lo dionisíaco y lo apolíneo marchan "casi siempre en abierta discordia entre sí y excitándose mutuamente a dar a luz frutos nuevos y cada vez más vigorosos" (Nietzsche, 1872/1994, pp. 41-42), hasta que finalmente, por un milagro metafísico de la voluntad helénica, se muestran apareados entre sí, y acaban engendrando la obra de arte a la vez dionisíaca y apolínea de la tragedia ática. Para ambos pensadores, las lógicas contradictorias son capaces, extraordinariamente, de fusionarse. En el contexto de El sacrificio de Narciso, en cambio, no hay conciliación posible entre amor y deseo: la expresión "amor erótico" es un "oxímoron" (Abadi, 2018, p. 20) y un "delirio" (Op. cit., p. 74). Como si fueran líneas paralelas, y no senderos que se bifurcan y trazan encrucijadas, deseo y amor se repelen: cuando se desea, no se ama; cuando se ama, no se desea. El deseo no admite estabilidad: es singular hasta el límite de lo impersonal y odioso de cualquier mismidad, incluida la propia. El amor, por el contrario, es compasivo y clemente. Si el deseo es imprevisible y no lo detiene consideración alguna por las expectativas y las ilusiones, el amor, complementariamente, es promesa y fidelidad. 
rev|Psi $\begin{aligned} & \text { Narciso y Eros en la cruz del presente } \\ & \text { Drivet }\end{aligned}$

Asociado a la piedad y al cuidado, el amor, en la constelación abadiana, se aproxima al a la caridad, al deber, a la ob-ligación y a la responsabilidad. ¿Tal vez a la culpa? Desprovisto de toda dimensión involuntaria (que le es atribuida al deseo) se asocia incluso a la capacidad de soportar el aburrimiento, y es definido como el "resto o sostén que hace falta cuando no hay deseo" (Abadi, 2018, p. 21). Abadi ofrece buenos argumentos para sostener esta tesis incómoda que ataca, precisamente, cierto orgullo "narcisista" sobre el amor y el deseo. Después de todo, es innegable que, agitado por las pulsiones parciales, el erotismo se asienta en un juego transitorio, seductor y riesgoso, de objetivación no sintetizable del amado y que, como contracara, el amor exige, a los fines de alojar a otro y hacer lazo, descentramientos, postergaciones y renuncias. Al mismo tiempo, hacia el final uno se pregunta si entre el deseo volátil y devorador, y el amor como el acto que sostiene y cuida, no hay matices, formas intermedias, combinaciones posibles menos evanescentes que el deseo, y menos abnegadas que este amor. ¿No hay acaso disposiciones relativamente estables a sentir deseo por alguien amado? ¿O confundimos la pura y azarosa renovación erótica con la regularidad? ¿Y no es conocida la inclinación a amar (como sujeto) al objeto deseado? Así como somos capaces de unirnos en el desprecio del "fuego sin lumbre" [the lightless fire] (Shakespeare, 2002, Luc 4, p. 243) ¿nos es dado crear un amor encendido?

Es tentador pensar que Eros personifica el deseo de un objeto, mientras que Narciso encarna el querer ser amado. Los extremos de este arco son mortificantes (para uno y/o para los otros), y su magnetismo amenaza con convertirnos en déspotas sin remordimiento o en esclavos de un ideal parasitario. No es que las zonas medias estén exentas de peligros, pero en nuestros días no es difícil de entender por qué el calor del erotismo que no guarda la más mínima expectativa de engendrar alguna forma de amor (por pequeña y transitoria que sea) se parece tanto al odio. La búsqueda de una aleación tal de amor y deseo, ¿no es quizá la verdadera superación de la tragedia de Narciso y de su antítesis, el absolutismo de Eros? Puesto que si aquel sacrifica su cuerpo en aras del amor a su imagen, no es menos cierto que destruye esa imagen al precipitarse sobre ella. ¿Deberíamos decir entonces que Narciso no ama, sino que desea su imagen?

El ensayo aquí reseñado puede leerse como una apuesta por el vivificante equilibrio inestable entre componentes antagónicos. Como un espejo invertido, trueca certezas por interrogantes, refracta nuestra mirada e incita a seguir. La multiplicación del preguntar en los lectores es acaso el mejor signo del carácter filosófico de una obra. 
$\operatorname{rev|Psi} \begin{aligned} & \text { Narciso y Eros en la cruz del presente } \\ & \text { Drivet }\end{aligned}$

\section{Referencias}

Abadi, F. (2018). El sacrificio de Narciso. Hecho Atómico Editores.

Freud, S. (1914/2003). Introducción del narcisismo. En S. Freud, Obras completas, Tomo XIV (trad., J. L. Etcheverry) (pp. 65-97). Amorrortu.

Freud, S. (1932/2006). Sobre la conquista del fuego. En S. Freud, Obras completas, Tomo XXII (trad., J. Etcheverry) (pp. 169-178). Amorrortu.

Nietzsche, F. (1872/1994). El nacimiento de la tragedia o Grecia y el pesimismo (trad., A. Sánchez Pascual). Alianza.

Ovidio Nasón, P. (1983) Metamorfosis (trad., A. Pérez Vega). Cervantes Virtual.

Platón. (1987) Menón. En Platón. Diálogos II. Gorgias, Menéxeno, Eutidemo, Menón, Crátilo (trad., F. J. Olivieri) (pp. 273-337). Gredos.

Plutarco. (1987). Moralia, charlas de sobremesa (Quaestiones convivales) (trad., F. Martín García). Gredos.

Shakespeare, W. (2002). The rape of Lucrece. En W. Shakespeare, The complete sonnets and poems (ed., C. Burrow) (pp. 243-338). Oxford.

Vernant, J-P. (1989/2001). El individuo, la muerte y el amor en la antigua Grecia (trad., J. Palacio). Paidós. 